\title{
Analysis of Applying Ultrasonic Frequency on a Desktop FDM Nozzle
}

\author{
Authors: Maidin, S. ${ }^{a}$, Abdul Aziz, K. F. ${ }^{\text {, }}$ Muhamad, M.K. ${ }^{a}$, Pei, E. ${ }^{b}$ \\ a Faculty of Manufacturing Engineering, Universiti Teknikal Malaysia Melaka, Hang Tuah Jaya, 76100 Durian \\ Tunggal, Melaka Malaysia \\ ${ }^{b}$ Brunei University London, College of Engineering and Physical Sciences, Department of Design, Tower A, \\ TOWA020 UB8 3PH, United Kingdom
}

To cite this: Maidin, S., Aziz, K.F.A., Muhamad, M.K. and Pei, E. (2015) "Analysis of Applying Ultrasonic Frequency on a Desktop FDM Nozzle", Applied Mechanics and Materials, Vol. 761, pp. 329-332

DOI: 10.4028/www.scientific.net/AMM.761.329

About the Co-Author: Eujin is the Programme Director for the BSc Product Design and BSc Product Design Engineering programmes at Brunel University London. He was a Research Fellow at leading institutions including Loughborough University, Brunel University and the University of Southampton; and was a Visiting Scientist to Vaal University of Technology and Central University of Technology, Free State His professional design consultancy work includes those for BAE Systems Applied Intelligence, Motorola, Inc., LM Ericsson, Sennheiser $\mathrm{GmbH} \&$ Co. KG, and Rentokil Initial, of which some products are still manufactured and sold today. $\mathrm{He}$ is the Convenor for the International Organisation for Standardisation (ISO) TC261/WG4 group, leading Data Transfer and Design Standards for Additive Manufacturing, as well as holding various positions within ISO committee for Additive Manufacturing standards. Eujin is also a Chartered Technological Product Designer (CTPD) with Institution of Engineering Designers in the UK.

Abstract. Fused deposition modeling (FDM) is an Additive Manufacturing (AM) process that has an economical advantage compared to other AM processes. However, its biggest drawback is that it requires post processing to achieve a good surface finish. Ultrasound has been applied in various conventional machining processes and produce good surface finish. However, the application of ultrasound to AM has not been sufficiently explored. This research aim to investigate the application of using ultrasound technology for a desktop FDM system. The idea is to transmit high vibration from the ultrasonic transducer to the FDM system's nozzle and the objective is to examine whether the nozzle is able to withstand the high vibration being transmitted. A Computer-Aided Design (CAD) software used to develop the 3D model of the extrusion nozzle component and a Computer-Aided Engineering (CAE) software was used to perform static and vibration analysis. A frequency range of $20 \mathrm{kHz}$ to $30 \mathrm{kHz}$ and $30 \mathrm{kHz}$ to $40 \mathrm{kHz}$ was applied to the nozzle and it was found that the nozzle was able to withstand frequencies up to $40 \mathrm{kHz}$ of vibration. In addition, the lowest Factor of Safety (FoS) obtained was 18.8975, concluding that the nozzle of FDM can withstand the high vibration transmitted from the ultrasonic transducer.

Keyword: Fused deposition modeling, Ultrasonic, Factor of Safety

\section{Introduction}

The surface finish of products is an important factor for both manufacturers and users. In a conventional manufacturing process the product surface finish can be improved by going through a sequence of finishing processes such as spray painting, sand-blasting, anodising, etc. [1]. The quality of the surface finish relates to aspect of appearance and its perceived aesthetic value. AM is a technology that allows users to build functional parts with complex 
geometrical shapes within a reasonable build time. FDM is a subset of AM where predetermined layers of extruded material are deposited to create a three dimensional geometry. AM parts largely depend on few process parameters such as dimensional accuracy, surface roughness, and mechanical strength [2]. However, the FDM process often encounter issues of surface finish due to seam lines that appear on the surface. One approach to improve the poor surface quality is to apply chemical treatment to the FDM part. However, this technique can be costly and also hazardous to undertake [3].

The use of ultrasound has become increasingly used in many industrial applications, and it is a proven technology being able to improve the quality of machined surface finish [4]. In ultrasonic machining, the tool vibrates at a high frequency usually higher than $20 \mathrm{kHz}$, and abrasive slurry is pumped between the work piece and the tool [5]. This process does not cause a chemical reaction and is therefore regarded to be safe and does not chemically corrode the work piece. Applying ultrasonic to FDM has not yet been explored and it has the potential to improve the surface finish of those parts. The nozzle is the essential component in the FDM system and a vibration analysis must first be carried out to ensure that the nozzle is able to withstand the high frequency of vibration.

\section{Methodology}

The dimensions of the FDM nozzle was measured and a 3D CAD model was reverse engineered. The Solidworks CAD software was used and Fig. 1 shows the exploded view of the FDM nozzle and Fiq. 2 shows the assembly view of FDM Nozzle. Table 1 shows the detail about each parts of the FDM Nozzle.

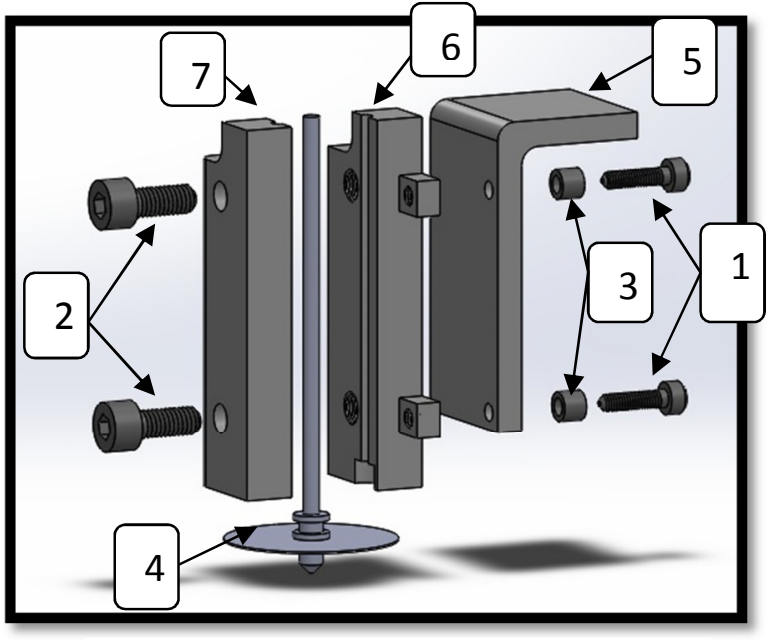

Fig. 1: Exploded View of FDM

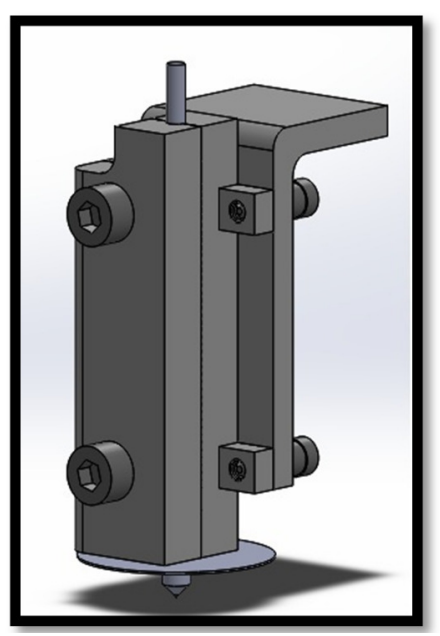

Fig. 2: Assembly View of FDM Nozzle

ANSYS is a CAE software that was used to run the simulation and analysis. The Solidworks file was saved in an IGES format to allow ANSYS to read the file. Static structural analysis was carried out to analyze the nozzle reaction of the force that was experienced. Total deformation of the FDM nozzle, virtual stress tests and the Factor of Safety (FoS) were obtained in the analysis.

Modal analysis was used analyze the reaction of the nozzle when subjected to the vibration from the ultrasonic transducer. The total deformation of the FDM nozzle and equivalent stress with frequency $20 \mathrm{kHz}-30 \mathrm{kHz}$ and $30 \mathrm{kHz}-40 \mathrm{kHz}$ were studied in this analysis. 
Table 1 shows the detail of each part of FDM nozzle including the parts name, the quantity, the volume $\left(\mathrm{mm}^{3}\right)$, the type of material and its density.

\begin{tabular}{|c|c|c|c|c|c|}
\hline No & Part & Quantity & Volume $\left(\mathbf{m m}^{3}\right)$ & Material & $\begin{array}{r}\text { Density } \\
\left(\mathrm{kg} / \mathrm{m}^{3}\right)\end{array}$ \\
\hline 1 & Cap screw M3 & 2 & 120.54 & \multirow{2}{*}{$\begin{array}{c}\text { Stainless } \\
\text { Steel }\end{array}$} & \multirow{2}{*}{7750} \\
\hline 2 & Cap screw M5 & 2 & 413.72 & & \\
\hline 3 & Bushing & 1 & 50.27 & \multirow{5}{*}{$\begin{array}{c}\text { Magnesium } \\
\text { Alloy }\end{array}$} & \multirow{5}{*}{1800} \\
\hline 4 & Extrusion nozzle & 1 & 444.87 & & \\
\hline 5 & Guider & 1 & 8134.91 & & \\
\hline 6 & Back clamper & 1 & 8728.59 & & \\
\hline 7 & Front clamper & 1 & 8373.06 & & \\
\hline
\end{tabular}

Table 1: Parts of the FDM Nozzle

\section{Result and Discussion}

Fig. 3 shows the equivalent stress of FDM nozzle for frequency $20 \mathrm{kHz}$ to $30 \mathrm{kHz}$. The highest value is $11.721 \mathrm{MPa}$ and the lowest value is $21.324 \mathrm{MPa}$. The Factor of safety (FoS) for this model was obtained by using this result. The calculations showed that the factor of safety of the model was 20.56, referring to the fact that the nozzle can withstand a frequency range of between $20 \mathrm{kHz}$ to $30 \mathrm{kHz}$ that will be transmitted from the ultrasound transducer. Even though the FoS is high, we observed that bending still took place on the nozzle due to the fact that the part has a thin thicjness profile. Our observations also showed that no loose screws were found on the part after being subject to vibrations.

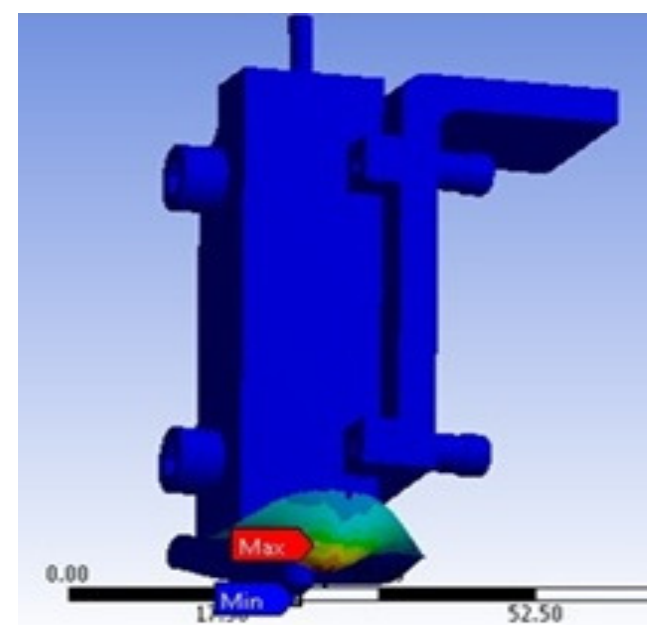

$$
\begin{aligned}
\text { FoS } & =\frac{\text { Ultimate tensile strength }}{\text { maximum stress }} \\
& =\frac{241 \mathrm{MPa}}{11.721 \mathrm{Mpa}} \\
& =20.56
\end{aligned}
$$

Fig. 3: Equivalent stress of FDM nozzle using frequency $20 \mathrm{kHz}$ to $30 \mathrm{kHz}$

Fig. 4 shows the equivalent stress of FDM nozzle for frequency $30 \mathrm{kHz}$ to $40 \mathrm{kHz}$. The highest value is $12.753 \mathrm{MPa}$ and the lowest value is $6.464 \mathrm{MPa}$. The FoS for this model was found to be 18.8975 , referring to the fact that the nozzle can withstand frequencies between $30 \mathrm{kHz}$ to $40 \mathrm{kHz}$ from the ultrasonic transducer. The FoS is higher than $20 \mathrm{kHz}$ to $30 \mathrm{kHz}$ because the ultimate tensile strength also higher. The ultimate tensile strength become higher because of the frequency applied is higher. The supposition is that having a higher frequency will result in a lower FoS for FDM nozzle. 


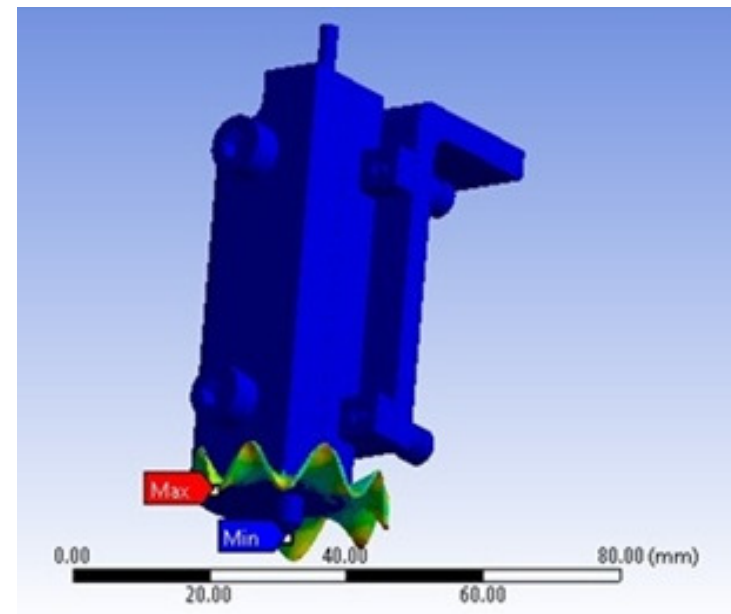

$$
\begin{aligned}
\text { FOS } & =\frac{\text { Ultimate tensile strength }}{\text { maximum stress }} \\
& =\frac{241 \mathrm{MPa}}{12.753 \mathrm{Mpa}} \\
& =18.8975
\end{aligned}
$$

Fig.4: Equivalent stress of FDM nozzle using frequency $30 \mathrm{kHz}$ to $40 \mathrm{kHz}$

\section{Summary}

From the results of the analysis, the FDM extrusion nozzle was found that it could potentially withstand frequencies up to $40 \mathrm{kHz}$. The lowest FoS that was obtained was 18.8975. The findings prove that the nozzle is structurally and mechanically strong enough to withstand the high frequencies transmitted from the ultrasonic system. High deformations occurred to the extrusion nozzle but not to the cap screws. our observations also found that the joints of the cap screws have remained secure throughout the process even after being subjected to a frequency of $40 \mathrm{kHz}$. The limitations of this study is that it only covers the impact of high frequency from ultrasonic transducer to a desktop FDM extrusion nozzle using simulation software. Therefore, an actual real-world study must also be carried to validate the findings where experiment will be done in greater depth to ascertain conclusive findings. Process parameters such as layer thickness, build density and the speed of build will be varied and will be investigated, along with material removal rate, accuracy, and the quality of surface finish. It is expected from this study that an ultrasonicassisted FDM process has the potential to achieve better surface finish of parts being produced.

\section{Acknowledgement}

The author are grateful for all the aid from all those who have helped during the author's study at the Universiti Teknikal Malaysia Melaka whether direct or indirectly to complete this project.

\section{References}

[1] Peiponen, K. E., Myllyla, R., \& Priezzhev, A.V. 2009. Optical Measurement Techniques: Innovations for Industry and the Life Sciences (Vol. 136). Springer, pp. 41

[2] Panda, S. K., Padhee, S., Sood, A. K., \& Mahapatra, S. S. 2009. Optimization of Fused Deposition Modelling (FDM) Process Parameters Using Bacterial Foraging Technique. Intelligent Information Management, 1(2). 
[3] Galantucci, L. M., Lavecchia, F., \& Percoco, G. 2009. Experimental Study Aiming to Enhance the Surface Finish of Fused Deposition Modelled Parts. CIRP AnnalsManufacturing Technology, 58(1), pp. 189-192.

[4] Nad, M. 2010. Ultrasonic Horn Design for Ultrasonic Machining Technologies. Applied and Computational Mechanics, 4(1).

[5] Wang, J., Shimada, K., Mizutani, M., \& Kuriyagawa, T. 2013. Material Removal During Ultrasonic Machining Using Smoothed Particle Hydrodynamics. Journal ref: International Journal of Automation Technology, 7(6), pp. 614-620. 